\title{
The Evaluation Model for Interior Design Organizational Technology Integration: The quality of the design aid and economic evidence and factors
}

\author{
Seungpok Choi* \\ Interior Design Dept. \\ Silla University, Busan, Korea
}

\begin{abstract}
Technological substitution is the process by which a radical technology replaces the dominant technology in an industry. The processes of diffusion and substitution have been modeled extensively (Technology \& innovation, 2010). However, the formulation of classical quantitative models encompasses only part of the theoretical space. These models impose many simplified constraints to the achievement of analytical resolution. The interior design organization needs to establish a set of technical system requirements by describing the scope of the accessibility needs of the organization against current technology use. Because of complicated design resources and ongoing advances in design technologies, design systems face the challenge of prioritizing new technologies for supporting. The problem is small design organization administration often displays a lack of concern toward the evaluation of technology integration. In this paper, I will identify the influence of a design organization's technology, and predict how future technology will inform, support, and potentially hinder productivity, culture, and work satisfaction within a design organization in the industry. In addition, I will use current design organizational behavior and leadership models to support my predictions. Finally, I will examine a proven approach to assist designers with evaluating technology integration in interior design organization. The goal is to develop a high quality, professional development scorecards for the evaluation. I will conduct both the evaluation of technology integration and CRM performance evaluation is recommended to assess the effectiveness of technology integration. Therefore, the evaluation of integration technologies oriented design hold the promise of solving the organization application integration challenge. The evaluation of integration technology is a significant pattern for processing such a vision. The careful selection of an integration technology for this purpose is crucial in contributing toward the success of such an interior design organization endeavor.
\end{abstract}

Keyword: Evaluation of integration technology, Interior design organization, design organizational behavior

\section{INTRODUCTION}

Technological substitution is the process by which a radical technology replaces the dominant technology in an industry. The processes of diffusion and substitution have been modeled extensively [36]. However, the formulation of classical quantitative models encompasses only part of the theoretical space. These models impose many simplified constraints to the achievement of analytical resolution.

The interior design organization needs to establish a set of technical system requirements by describing the scope of the accessibility needs of the organization against current technology use. The designer's, developers, and leaders thoughts and intuitions about innovations are not to be solely relied upon. The users' needs and behaviors are to be considered vital. User-centered approaches and data gathering methods can be used to identify critical requirements for developing new products and services. In terms of research, there is a need to delve deeper into the process of consolidating

\footnotetext{
* Corresponding author, Email: sweet@silla.ac.kr Manuscript received Oct. 27, 2011; revised Feb. 28, 2012; accepted Mar 02, 2012
}

and translating data into systems requirements [8]. I will describe a practical approach to develop the evaluation of technology integration in design organization.

To design the evaluation and considerations used for prioritizing new design technologies, and to conduct both the evaluation of technology integration and CRM performance evaluation to demonstrate a method for deriving relative weights for the evaluation. And then, based on this review, and primarily for the purpose of demonstrating the method, I will derive weights for a set of evaluation related to the benefits from technology. This paper will conduct both the evaluation of technology integration and CRM performance evaluation that recommend assessing the effectiveness of technology integration.

\section{PROBLEM STATEMENT}

Because of complicated design resources and ongoing advances in interior design technologies design systems face the challenge of prioritizing new technologies for supporting. The problem is small design organization administration often displays a lack of concern toward the evaluation of technology 
integration. Unfortunately, most attempts at explicitly prioritizing technologies at the macro level have been criticized for inadequately identifying their values, principles, and other normative concepts and for their values frameworks by employer or senior designers [29]. In addition most of the interior design company failed because of inadequate customerfocused strategy [20]. As the organization increases contact with the consumer, by increasing its own efforts, the chances of forming a relationship with the consumer also increase proportionally [2].

Building the evaluation of technology integration in the organization is difficult. These evaluation need to integrate multiple business systems not intended to work together. Integrating such technology systems is hard for many reasons. These include the heterogeneity of the platforms and programming languages, the diversity and complexity of each individual design organizational system, and the difficulty of understanding the requirements for the resulting integrated solution.

\section{PURPOSE STATEMENT}

The purpose of this study is to examine a proven approach to assist interior designers with evaluating technology integration in design organization. The goal is to develop a high quality, professional development scorecards for the evaluation. I will conduct both the evaluation of technology integration and CRM performance evaluation is recommended to assess the effectiveness of technology integration. In particular, I will focus on evaluating integration technologies, for implementing understand the functional and quality requirements for the integrated applications and validating that the combination of the design and the integration technology used to build the enterprise-wide application are likely to be successful before a major implementation investment is made. This study's findings and discussions will assist designers in the effective evaluation of professional technology integration in interior design organization. Any attempt to evaluate technology integration and instruction must have necessity examine what was the content focus of the professional development and what were the measures used to ascertain whether that technology integration had an impact on designer knowledge and behavior and specific CRM outcomes [1].

\section{TECHNOLOGY AND INTERIOR DESIGN ORGANIZATION BEHAVIOR}

Technology used in an interior design organization can affect an organizational culture either positively or negatively. The availability of resources can make designers' work more productive or daunting. A technology professional, depending on a few contributors can facilitate the health of an organizational culture. However, there are burdens that influence an effective culture to include an unsupportive culture, limited funding, workforce issues, process immaturity, insufficient access to information and data [30]. Organizational cultures shape the way in which organizations choose to use technology. Technology is an influential tool, and social, cultural, and economic factors regulate the influence it has on organizations [22].

\subsection{Organizational culture}

Implementing new techniques and methods within interior design organization will re-shape existing organizational culture. The key is to administer these changes without undermining the existing corporate culture. The changes a company wants to make cannot be done because the proposed changes go so much against the company culture that it will only result in a decline in productivity and the loss of good designers. Workplace environment has become the number one issue for designers, especially skilled designers. Everyone wants to be in a "good place to work". Therefore, designers are today's primary competitive advantage, and sustain the type of culture that they seek out [14].

\subsection{Knowledge management systems}

Knowledge management systems will affect the organizational learning. Knowledge management systems enable learning in a design organization and facilitate a knowledge-based organization. Knowledge management is a long-term process that rarely gives immediate returns on investment. Many contemporary organizations seek to maintain a decentralized entrepreneurial culture and implement an organization-wide knowledge sharing and learning strategy. This strategy involves knowledge capture and transfer particularly tacit knowledge as well as explicit knowledge. Knowledge management can establish and reinforce connections between individuals. Evolving the organization structure is facilitated by knowledge sharing technology as a critical element to knowledge management practices [33].

The technology will encourage the free flow of information. For example, newer types of IT such as electronic mail and groupware are creating substantial changes in the way that information runs around group ware, and among designers, and their customers and suppliers. It can accelerate the development of more open and innovative cultures [37]. Moreover, design organizations build an intranet because it's a sprightly, competitive tool, powerful enough to reduce time, shrink the disadvantages of distance, and build on their greatest capital asset - designers with knowledge of company operations and products [16].

\subsection{Information sharing technology}

Information sharing technology will facilitate a culture of collaboration. Organizational culture and beliefs about the suitability of technology affects the acceptance [26]. Interior design organization uses groupware products that contain schedulers, calendars, e-mail and real-time meeting functions. Groupware products usually have a shared database where designers can work on common documents and conduct electronic discussions and meetings. Groupware products can most simply be defined as teamwork software. Groupware products usually have a shared database where designers can 
work on common documents and conduct electronic discussions and meetings. Groupware allow team members to work on a document, discuss ideas online, maintain records, and prioritize, and schedule teamwork and meetings. Many design companies will use groupware packages to increase designers' productivity because they allow for collaboration on projects and provide a place to share their ideas on design process [19].

Collaborative design, as with design iteration will be a keystone for design excellence. At integrated multidisciplinary design and technical expert teams from across the company work in multiple office locations to provide design services. Correctly evolving to use technology to deliver outstanding design to clients while collaborating with partners and developing new talent can mean the difference between being better positioned and more profitable or being left behind. In interior design organization, computer-aided design (CAD) is transforming the way we design. In a relatively short time, using this technology for designing buildings has challenged conventional thinking and begun to create a new standard for the entire industry. For many people, rapid change can be difficult, and nearly all culture changes take time. Implementing CAD across the firm needs to be seen as more evolutionary than revolutionary. Perhaps more important than the technology implementation, designers will discover the positive impact as well as some of the challenges that technology has on our design culture, our design process, and how it can help us achieve design excellence.

Furthermore, Technology may foster collaboration and interactivity cross-functionally, it cannot by itself create a knowledge sharing culture. The technology used can affect the organizational culture to continue with staying competitive in the marketplace [30]. In addition, technology affects diversity within organizations because diverse talent can provide insights and develop creative solutions to technology problems. Engaging other field of designers within the organization can create organizational culture that promotes shared knowledge and learning while increasing services to customers and saving the organization in the future.

However, the operations of such technologies may have been done for the best of reasons, but many times they have a negative outcome on the design organization and its productivity. For example, there are many ways that companies can monitor designers. Many companies say that they monitor designers' online activity to avoid liability and maintain productivity. Because of the increase in Internet access made available to designers, companies are verdict that designers are spending time online for nonworking-related issues [13]. Most of monitoring tools only scan e-mail and forbid access to certain Web sites [14]. Therefore, effectively managing designers Internet use and ensuring that they're using the tool for business purposes only requires a balanced blend of technology, policy, and culture.

Designers should have some level of privacy at work and managers should not be allowed to open completely private emails. Any computer use policy should include a system for marking personal versus business email to alleviate confusion, or clearly state that e-mail is subject to monitoring. Given the risk of legal liability, productivity loss, and drain on bandwidth, organizations must implement acceptable use policies and monitor resource usage. Therefore, managers and technology professionals must take steps to ensure the negative impact is minimized [34].

\subsection{Technology in future}

A major change in technologies can cause an interruption in behavior patterns throughout departments or sections of an organization. New learning prospects often cause some levels of cognitive dissonance for a time. Design organization members may fail their ability to be effective during others will be more effective because of the technological changes [39]. "Technological information is power" still reigns large in many design organizations, many new systems fail to become recognized by designers such as users because the systems developers have not been culturally sensitive to the department or group ware, in which the new systems are to be used [37]. Therefore, the use may reshape how each of the designers operates based on expectation of the organizational leaders. Some designers may be more acceptable to technology as others may find it more of a nuisance and reject its use causing the organization to be less effective

In organizational behavior, designers to gain a deeper understanding of users' culture and find strategies on how they can use culture as a resource in product development and promote culture -orientated product innovation. Culture-driven research technology provides new knowledge, ways of thinking and dealing with design issues and laying the groundwork for creativity and erecting the structure for product innovation. It ensures that design solutions matches users' needs, abilities, and desires. However, new technologies succeed only when they resonate with users' values, attitudes, and behaviors, even if they result in changes to the same values and behaviors. This consideration should occur at the very early stages of conceptual development when the concept is still relatively fluid. The input from socio-cultural factors is not sufficient to generate culturally innovative and acceptable solutions but one need to incorporate data from physical, cognitive, and emotional human factors. The challenge for designers will use new technology that designers will want to keep, maintain, and use for longer periods.

Furthermore, the designer at work and home would work to control the permeability of the borders. Developments in communication technologies radically have changed designers' methods of balancing work [10]. Whereas technology-mediated devices have allowed workers to work almost anytime and anyplace, facilitating workers' ability to integrate the home and work domains, these tools have also allowed each domain to more frequently intrude into the other. Boundary theory [6] suggested that designers have distinct preferences for the level of integration of their work and home roles, and will seek to achieve that desired level of integration. Therefore, workplace policies and norms, individual preferences, family norms, and expectations, gender, and generation are antecedents of connectivity behaviors between home and work that will utilize communication technologies to bridge the boundaries between home and work.

In leadership models, design managers need to identify 
situations that require varying their management style, and a way to determine the individual, developmental levels of designers. I may suggest, Blanchard (1991), situational leadership model to help design organization [9]. It is supportive and directive behavior with respect to the designer's development level [12]. Design managers can put the model to practical use. First, this model shows how managers must vary their leadership style to match both the situation and the developmental level of their designers' proceeds. These are the "situations" that command differing levels of directive and supportive behavior from managers [9]. Designers also need to apply the concept to specific behaviors and properties of each "situation" in order for them to put Blanchard's model to use. Therefore, if design managers learn how to identify each of their designers' developmental level, and alter their management style to the situation at hand, they will be wellequipped to manage their designers better and achieve favorable results. Applying Blanchard's Situational Leadership can make design job much easier and results more predictable [12].

\section{MATERIALS AND METHOD}

A variety of methods will be employed to address the research problems, including a program evaluation model and scorecard. The dashboards and scorecards have proven to be effective to help leaders to determine the state of projects and the likely success of technology. Summarized information and key performance indicators provide visibility into business performance relative to financial and strategic plans [11]. The use of multiple assessments will provide source triangulation [27] and enabled the researchers to make useful recommendations for program improvement [4]. An important element of the scorecard approach is the cascading of the scorecards from corporate levels of an organization through to individual units, and the integration of the individual business unit scorecards to inform the scorecard at the corporate level [1]. CRM solutions that tie directly into other systems are particularly powerful because institutions can take customers through a closed-looped set of well defined steps and processes to satisfy their needs [35]. CRM business strategy and associated technologies can hone in on facilitating customer interaction. This can contribute to the implementation of the evaluation into strategic and manageable projects. Different evaluation from times past customer management is a competitive advantage as customers are deemed priority. Therefore, this paper will conduct both the evaluation of technology integration and CRM performance evaluation that recommend assessing the effectiveness of technology integration.

\subsection{Design of the evaluation of technology integration}

Design organization uses to assess the benefits of technology include: (a) Need (appropriateness and design benefits), (b) Efficiency (including cost-effectiveness), (c) Equality (solidarity and social values) [25], and (d) Flexibility (customers' perspective) [5]. The quality of the design aid and economic evidence and factors related to strategic issues and procedural justice respectively are also considered (Table 1). The assessment model is considered to be a comprehensive performance-measurement system. The allure of the measurement system is providing a framework that allows design organization to assess its performance from financial and nonfinancial aspects pertaining to design organizational benefits and concerns. In the complex and rapidly changing environment, financial measurements, such as return on capital and net profit rates, are considered to be short-term measurements. These measurements are not sufficient in measuring the organizational benefits concerning technology and organizational performance [25].

The use of the information technology enables the efficient e-design to serve internal customers in design organization. 'Need' is most commonly defined in terms of the degree of appropriateness and design benefits. The meaning of these terms varies according to how design benefits are assessed and usually expressed in terms of the technology's effectiveness or appropriateness. Efficiency-based criteria are common to all design organization. Most design organization relates explicitly to cost-effectiveness or cost-benefit considerations. In an equality-based criterion, other ethical or social considerations explicitly referred to by decision-makers include autonomy, public design value, and impact on future generations. The quality of the design factors related to strategic issues and procedural justice respectively need to be also considered. A flexibility-based criterion is based on customers' prospective. Customer Relationship Management (CRM) software solutions aim to eliminate the organizational stovepipes that hamper proactive customer interaction and is designed to increase the effectiveness of employees who interact with customers [35]. Even more so these types of applications can improve customer responsiveness. It can also lead to a more comprehensive view of the entire "cradle-to-grave" customer life cycle [35]. Users' tend to make decisions based on behavior based on desires or motives [8]. Motives are extremely important in the context of IT development, because knowing what motivates people to use a product or service becomes central, especially when the product or service is aimed at private and voluntary use [8]. Translation of users' expectation can be viewed as - needs of a service and needs in a service (Table 1).

Table 1.Organizational Technology Integration Evaluation

\begin{tabular}{|c|c|c|}
\hline Variables & Characteristic & Evidence in Materials \\
\hline Need & $\begin{array}{l}\text { Appropriatenes } \\
\text { s and design } \\
\text { benefits }\end{array}$ & $\begin{array}{l}\text { - 'Need' is most } \\
\text { commonly defined in terms of } \\
\text { the degree of appropriateness } \\
\text { and design benefits. } \\
\text { - The meaning of these } \\
\text { terms varies according to how } \\
\text { design benefits are assessed } \\
\text { and usually expressed in terms } \\
\text { of the technology } \\
\text { effectiveness or } \\
\text { appropriateness. }\end{array}$ \\
\hline Efficiency & $\begin{array}{l}\text { Including cost- } \\
\text { effectiveness }\end{array}$ & $\begin{array}{l}\text { - Efficiency-based } \\
\text { criteria are common to design } \\
\text { organization. } \\
\text { - Most design }\end{array}$ \\
\hline
\end{tabular}




\begin{tabular}{|c|c|c|}
\hline & & $\begin{array}{l}\text { organization relates explicitly } \\
\text { to cost-effectiveness or cost- } \\
\text { benefit considerations. }\end{array}$ \\
\hline Equality & $\begin{array}{l}\text { Solidarity and } \\
\text { social values }\end{array}$ & $\begin{array}{l}\text { - In an equality-based } \\
\text { criterion, other ethical or } \\
\text { social considerations } \\
\text { explicitly referred to by } \\
\text { decision-makers include } \\
\text { autonomy, public design } \\
\text { value, and impact on future } \\
\text { generations. } \\
\text { - The quality of the } \\
\text { design factors related to } \\
\text { strategic issues and procedural } \\
\text { justice respectively need to be } \\
\text { also considered. }\end{array}$ \\
\hline Flexibility & $\begin{array}{l}\text { Customers' } \\
\text { perspective }\end{array}$ & $\begin{array}{l}\text { - A flexibility-based } \\
\text { criterion is based on } \\
\text { customers' prospective. } \\
\text { - Customer Relationship } \\
\text { Management (CRM) software } \\
\text { solutions aim to eliminate the } \\
\text { organizational stovepipes that } \\
\text { hamper proactive customer } \\
\text { interaction and is designed to } \\
\text { increase the effectiveness of } \\
\text { employees who interact with } \\
\text { customers [35]. } \\
\text { - These types of } \\
\text { applications can improve } \\
\text { customer responsiveness. - It } \\
\text { can also lead to a more } \\
\text { comprehensive view of the } \\
\text { entire "cradle-to-grave" } \\
\text { customer life cycle [35]. } \\
\text { - Translation of users' } \\
\text { expectation can be viewed as } \\
\text { - needs of a service and needs } \\
\text { in a service. }\end{array}$ \\
\hline
\end{tabular}

Table 2 Organizational Technology Integration Evaluation Scale

\begin{tabular}{|c|l|c|c|c|c|}
\hline $\begin{array}{c}5=\text { perfec } \\
\text { tion }\end{array}$ & $\begin{array}{l}4=\text { alm } \\
\text { ost } \\
\text { always }\end{array}$ & $\begin{array}{c}3=\text { freque } \\
\text { ntly }\end{array}$ & $\begin{array}{c}2=\text { someti } \\
\text { mes }\end{array}$ & $\begin{array}{c}1= \\
\text { seldom }\end{array}$ & $\begin{array}{c}0= \\
\text { almost } \\
\text { never }\end{array}$ \\
\hline
\end{tabular}

Table 3Organizational Technology Integration Evaluation Scorecard

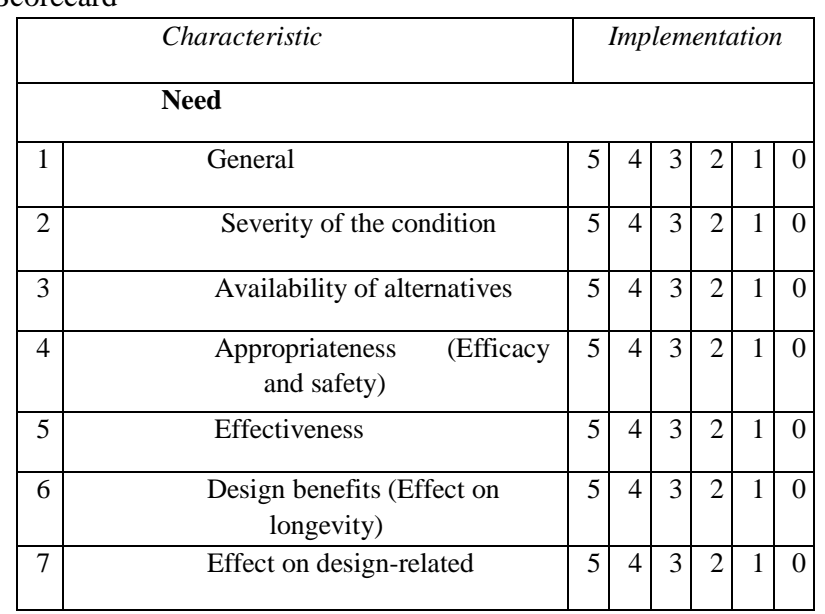

\begin{tabular}{|c|c|c|c|c|c|c|c|}
\hline 8 & quality-of-life & 5 & 4 & 3 & 2 & 1 & 0 \\
\hline \multicolumn{8}{|c|}{ Efficiency } \\
\hline 9 & Cost-effectiveness/benefit & 5 & 4 & 3 & 2 & 1 & 0 \\
\hline 1 & Budgetary impact & 5 & 4 & 3 & 2 & 1 & 0 \\
\hline 0 & & & & & & & \\
\hline 1 & Cost & 5 & 4 & 3 & 2 & 1 & 0 \\
\hline 1 & & & & & & & \\
\hline \multicolumn{8}{|c|}{ Equality } \\
\hline 1 & General & 5 & 4 & 3 & 2 & 1 & 0 \\
\hline 2 & & & & & & & \\
\hline 1 & Accessibility to the service & 5 & 4 & 3 & 2 & 1 & 0 \\
\hline 3 & & & & & & & \\
\hline 1 & Affordability to the individual & 5 & 4 & 3 & 2 & 1 & 0 \\
\hline 4 & & & & & & & \\
\hline 1 & Solidarity & 5 & 4 & 3 & 2 & 1 & 0 \\
\hline 5 & & & & & & & \\
\hline \multicolumn{8}{|c|}{ Other ethical or social values } \\
\hline 1 & Autonomy & 5 & 4 & 3 & 2 & 1 & 0 \\
\hline 6 & & & & & & & \\
\hline 1 & Public design value & 5 & 4 & 3 & 2 & 1 & 0 \\
\hline 7 & & & & & & & \\
\hline 1 & Impact on future generations & 5 & 4 & 3 & 2 & 1 & 0 \\
\hline 8 & & & & & & & \\
\hline \multicolumn{8}{|c|}{ Flexibility (customers' perspective ) } \\
\hline 1 & CRM perspective & 5 & 4 & 3 & 2 & 1 & 0 \\
\hline 6 & & & & & & & \\
\hline 1 & Customer satisfaction & 5 & 4 & 3 & 2 & 1 & 0 \\
\hline 7 & & & & & & & \\
\hline
\end{tabular}

\subsection{Evaluation model and other consideration}

Assessing the quality of the design aid is the first stage of technology assessment, and good evidence is a precondition for reimbursement [15]. Nonetheless, especially for some emergent design that technology can't do, a technology may be admitted for prioritization despite relatively poor evidence. In these special cases decision-makers may need to accept a lower quality of evidence in return for the perceived promise of benefit for clients with very serious conditions [25]. Quality of the design aid is mentioned relatively rarely as a criterion for prioritizing technologies in my interior design fields. Serving as a screening criterion before the prioritization stage needs to be reached. Several other considerations related to strategic issues and procedural justice respectively was mentioned for my interior design industry. The one priority for new technology and designers' preference more generally are also considered, and the other potential for long-term benefits to the organizational system is also taken into account. Considerations of procedural justice, in particular consistency with previous decisions and precedents, are mentioned for interior design industry.

In interior design organization, data collection and analysis are important processes in our routing-business practice. 
Designers collect the inquiry data from the products and materials from our internal costumers. Designers collect data in accordance to the needs of our suppliers and design and coordinate the demand with internal customers and business partners to fulfill the business-transaction processes. Design organization evaluates these actions as internal business processes included in designers performance-measuring system. The performance of the internal-business processes can be assessed by using key performance indicators [7]. Key performance indictors provide benchmarking information against similar companies for assessing the internal process performance. Strategic performance management can provide the organizational feedbacks needed to drive continual improvement, competitive status, and deliver superior performance efficiently [7]. Using a balanced measuring system enables the support of the definition, analysis, visualization, and interpretation of key performance indicators to increases the effectiveness of managerial strategy finding and implementation. Additionally, according to Bansal (2009), it is recommended that the experienced outside consultants conduct these reviews. Per definition, reviews are done by an external specialist, not by the project team. Specialists not involved in the day-to-day business of the project visit as independent and objective auditors to assess the status and progress of all activities. They identify potential risks to the project goals and recommend appropriate corrective actions [7].

The company looks at previous technology and compares it to what we have to see if the system works better, and it meets the objectives it intended. If designers complain that the new technology is not working as intended, the company would look at new ways to improve it. The company used the concepts of the Rodger's Diffusion theory that provides a meaning approach to making innovations visible to the public. By understanding the principles and using them, organizational leaders can get their products in the marketplace and there may be a high probability that they may be adopted by the consumers. Basically, if decision makers can test the innovation without making a full commitment, doubt is reduced, and therefore, the possibility of acceptance rises [3].

Furthermore, organizational leaders who fail to determine how technologic innovations will fit their organization do not position the innovation for success. Shane (2009) suggested that entrepreneurs or managers must manage technologic innovations in a manner where his or her employees communicate, are incentivized appropriately, link the technology with the organizational goals, and are in an environment that supports an innovative culture [30]. Through this recipe for success leaders are given specific guidelines to research in an effort to affect positive change. Innovation does not occur in seclusion [21]. Therefore, a collection of pertinent information is necessary for successful implementation. Managers should do to position the technologic innovation for success.

\section{FUTURE DIRECTIONS FOR RESEARCH}

Further research into the implementation of the methodology for real-life prioritization decision-making seems worthwhile. Redesign of the criteria and a randomly selected sample and material representative of the relevant population for the CRM criteria would be required. The next step would be a pilot study of the overall prioritization approach, including the process outlined in the previous subsection, applied to real technologies in a real decision-making setting, perhaps alongside a conventional method for comparison purposes.

\section{CONCLUSION}

The model and scorecards(Table 3) presented in this research study emerges from the studies that included evaluation activities found in the literature as well as the researchers' knowledge and experiences in design organization, and presents evaluation that must build on each other to complete an effective evaluation of technology integration in interior design organization.

Our study sought to contribute to a consideration of the major evaluation for prioritizing new design technology integration and how their relative weights may be determined. The criteria discovered represent a pluralistic combination of needs-based and maximizing characteristics. The main advantage of this approach is involving practically specifying criteria and their weights, and also recognizing other considerations for prioritization in contrast to current prioritization methods, the evaluation offers clear guidance for weighing and balancing identified principles and criteria against each other.

Integration technology is highly technical, complex, and diverse collections of products that typically operate in design business environments. The design-based integration approach holds the key to seamless integration and interoperability in the future [5]. The evaluation of integration technologies oriented design hold the promise of solving the organization application integration challenge. The evaluation of integration technology is a significant pattern for processing such a vision. The careful selection of an integration technology for this purpose is crucial in contributing toward the success of such an interior design organization endeavor.

\section{REFERENCES}

[1] Abdullah, S., \& Al-Mudimigh. (2009). CRM scorecardbased management system: Performance evaluation of Saudi Arabian banks. Journal of Digital Asset Management, 5, p. 347 - 351.

[2] Ahuja, Vandana, Medury, \& Yajulu, (2010). Corporate blogs as e-CRM tools - Building consumer engagement through content management. Journal of Database Marketing \& Customer Strategy Management, 17(2), p. 91-105

[3] Alkhateeb, F. M., Khanfar, N. M., \& Loudon, D. (2010). Physicians' Adoption of Pharmaceutical E-Detailing: Application of Rogers' Innovation-Diffusion Model. Services Marketing Quarterly, 31(1), 116-132. doi:10.1080/15332960903408575

[4] Ann, E., Kara, D., \& Diane, y. (2009). Peer coaching and 
technology integration: an evaluation of the Microsoft peer coaching program. Mentoring \& Tutoring: Partnership in Learning, 17(1), p. 83-102

[5] Anna, L., \& Ian, G. (2005). Process and Criteria for Evaluating Services-Based Integration Technologies. Architecture Journal. Retrieved October 23, 2011 from http://msdn.microsoft.com/en-us/library/aa480046.aspx

[6] Ashforth, B., Kreiner, G., \& Fugate, M. (2000). All in a day's work: Boundaries and micro role transitions. Academy of Management Review, 25, p. 472-491.

[7] Bansal, S. (2009). Technology Scorecards: Aligning IT Investments with Business Performance, $\left(1^{\text {st }}\right.$ ed.). Hoboken, NJ: Wiley

[8] Bergvall-Kåreborn, B., \& Ståhlbröst, A. (2010). USER EXPRESSSIONS TRANSLATED INTO REQUIREMENTS. Human Technology, 6(2), 212-229. Retrieved from EBSCOhost on October 21, 2011.

[9] Blanchard, K. (1991). The One Minute Manager. New York: William Morrow

[10] Clark, S. (2000). Work-family border theory: A new theory of work-family balance. Human Relations, 53, p. 747-770.

[11] Cochrane, M. (2009, May 1). The Big Picture: Industry convergence mandates a holistic BI and performance management approach Information Management., 19(4), 38.

[12] Cody, B. (2002). Technical Management with Situational Leadership. The Arrington Group, Inc. Retrieved September 30, 2011 from http://The-ArringtonGroup.com

[13] Corcoran, C. K., \& Cotter, R. D., (2000). Client advocacy: Client-centric approach to technology and related services. Proposed paper for conference presentation at Educause 2000. Available on line: http://www.msu.edu/ corcora1 /edprop2000.html.

[14] Deal, J. (1999). Workplace Atmosphere: the Ultimate Coporate Advantage? Healthy Workplace. Retrieved September 30, 2011 from http://besser.tsoa.nyu.edu/impact/f99/Papers/gunasegara m.html

[15] Eddy, D (2009). Health technology assessment and evidence-based medicine: what are we talking about? Value in Health, 12(2). p. 6-7.

[16] Greer, T. (1999). Intranets: Changing Corporate Culture, Microsoft TechNet, Retrieved September 28, 2011 from http://www.microsoft.com/technet/intranet/corpcult.htm

[17] Hitt, M.A., Freeman, R. E, Harrison, J. S. (Eds) (2001) Handbook of Strategic Management. Massachusetts: Blackwell Business

[18] Marla, R. (1999). The effects of new technology on corporate culture. Retrieved September 28, 2011 from http://besser.tsoa.nyu.edu/impact/f99/Papers/gunasegara m.html

[19] Master Class, (1999).CIO Enterprise Magazine, Retrieved September 29, 2011 from http://besser.tsoa.nyu.edu/impact/f99/Papers/gunasegara m.html

[20] McLaughlin, S. (2009). The imperatives of e-business: Case study of a failed project. Journal of Business
Strategy, 30(1), 40-49.

[21] Meux. (2011). Expanding on the basics. The impact of technology on organizations. Retrieved from UOPX Online Classroom on September 19, 2011.

[22] Melitski, J., Gavin, D., \& Gavin, J. (2010). TECHNOLOGY ADOPTION AND ORGANIZATIONAL CULTURE IN PUBLIC ORGANIZATIONS. International Journal of Organization Theory \& Behavior (PrAcademics Press), 13(4), 546-568. Retrieved from EBSCOhost on September 28, 2011

[23] Merle, B. (2009). BIM's Effect on Design Culture. Retrieved September 30, 2011 from http://www.di.net/articles/archive/bims_effect_on_design culture/

[24] Noack, D. (1999). Nearly a Third of Firms Monitor Workers Online, APB Online. Retrieved September 28, 2011 from http://besser.tsoa.nyu.edu/impact/f99/Papers/gunasegara m.html

[25] Ofra, G., Paul, H., Giora, K., \& Orna, T. (2010). Health Technology Prioritisation: Which criteria for prioritizing new technologies, and what are their relative weights? University of Otago Economics Discussion Papers, 1006, p. $1-20$

[26] Parsons, S., Daniels, H., Porter, J., \& Robertson, C. (2006). Resources, staff beliefs and organizational culture: Factors in the use of information and communication technology for adults with intellectual disabilities. Journal for Applied Research in Intellectual Disabilities, 21(), 19-33.

[27] Patton, M.Q. (2002). Qualitative evaluation and research methods (2nd ed.). Thousand Oaks, CA: Sage.

[28] Richie, M., Vesna, P., \& Anne, H. (2010). Cultureorientated Product Design. Retrieved September 30, 2011 from

http://www.sd.polyu.edu.hk/iasdr/proceeding/papers/cult ure-orientated\%20product\%20design.pdf.

[29] Sabik, L., \& Lie, R. (2008). Priority setting in health care: lessons from the experiences of eight countries. International Journal for Equity in Health, 7(4).

[30] Shane, S. A. (2009). Technology strategy for managers and entrepreneurs. Upper Saddle River, NJ: Pearson/Prentice Hall.

[31] Simon, L. A. K., (2000, Spring). Touching the Future. New Educator, 6 (1).

[32] Strong, D. M., \& Volkoff, O. (2010). Understanding organization - enterprise system fit: A path to theorizing the information technology artifact. MIS Quarterly, 34(4), p. 731-756

[33] Talebi, K. (2009). Reconciling entrepreneurial culture with knowledge management and organizational learning. PWASET, 3(7), p. 496-500.

[34] Tanya, G., \& Dale, Y. (2005). Workplace Surveillance and Employee Privacy: Implementing an Effective Computer Use Policy. Communications of the IIMA, 5(2), p. 57-66

[35] Elaine, D. \& Margaret, O. (2011). Customer Relationship Management and Higher Education -A Vision. Advances in Management, 4(3), 18-20. Retrieved from EBSCOhost 
on October 22, 2011.

[36] Technology \& innovation management: Conference Paper Abstracts. (2010). Academy of Management Annual Meeting Proceedings, 1-103. doi:10.5465/AMBPP.2010.54509556

[37] The Impact of IT on Organizations. (2011). Retrieved September 27, 2011 from http://www.skyrme.com/insights/5itorg.htm

[38] Tidd, J., Bessant, J., \& Pavitt, K. (2005) Managing innovations: Integrating technological market and organizational change. ( $3^{\text {rd }}$ ed.). New Jersey, John $\mathrm{H}$. Wiley \& Sons

[39] University of Phoenix. (2011). Week 5 lecture: Forecasting Change and Behavior in Organizations. Retrieved September 30, 2011 from University of Phoenix, Org/726

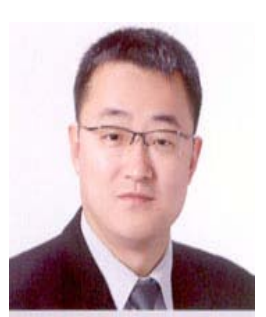

\section{Seungpok Choi}

He received the B.F.A., M.S in interior design from Pratt Institute, New York, US in 1995, 1998 respectively and is also continually studying Ph.D. in Management from university of Phoenix, US. Since then, he has been a professor of interior design department at Silla University in Korea. His main research interests include designing theme park and the aging facility, and design management. 